\title{
Research on GIS Based Reservoir Resettlement Data Management System - An Example of Guangdong Reservoir Resettlement Project
}

\author{
Jiexi Shen ${ }^{1 *}$, Bailing Zhou ${ }^{2}$ \\ ${ }^{1}$ Business School of Hohai University, Nanjing, China, 211100. \\ ${ }^{2}$ State Grid Electric Power Research Institute, Nanjing, China, 211100. \\ * Corresponding author. Tel.: +86 15295537632; email: jxshen37632@163.com \\ Manuscript submitted October 3, 2015; accepted March 8, 2016. \\ doi: $10.17706 /$ jcp.12.3.230-237
}

\begin{abstract}
Reservoir resettlement management is the fundamental project to the success of construction of reservoir. Due to the diversity of types of engineering data and trivial content as well as wide range of covers, modern technologies like GIS are required to build the information system and to achieve systematic management of data which can be displayed through diverse methods in order to satisfy requirements of people from different backgrounds. This paper introduced the application module of reservoir management system and gave an example of practical application in Guangdong Province, aiming at demonstrating high effectiveness, systematicness and convenience of modern technologies in reservoir resettlement project management.
\end{abstract}

Key words: Data management, reservoir resettlement, GIS, Guangdong Province.

\section{Introduction}

Reservoir resettlement management project is a quite complex system with diverse types of data involving respects including society, economy, politics, culture and environment. The unique is in that mass migration of the whole village, town and county is closely connected to socio-economic system reconstruction [1]. Traditional management approach based on paper brought about fragmentations in information management of reservoir resettlement. What is worse, data can hardly be updated and certain key information might be missed if it merely relies on paper work when the process of reservoir construction is approaching and the amount of data is increasing.

It has become a common sense among reservoir management department that to establish a systematically and real-time effective information management system with integrity can, on the one hand, facilitate the upper administrative departments issued rules and regulations, on the other hand, provide channels for immigrants' supervision on the progress in the project and help decision makers regulate more convenient rules.

GIS has a wide range of application in different aspects including national security and fuzzy territorial border conflict [2]; underground water quality, water measurement and urban water supply service [3]; observing the physiological activity of a population and taking actions to protect endangered species [4], etc. Implementing GIS into reservoir resettlement will definitely improve the efficiency of migration management work as well as ensure the smooth process of resettlement project. 
The first part in this paper will mainly focus on the introduction of application module of terminal supervision data management; the second part will deal with the practical application of this system in Guangdong reservoir immigration project; conclusion will be drawn in the last part.

\section{Application Module}

\subsection{Data Source Management}

The core for the management of reservoir resettlement and later support project is data. The fundamental function for the terminal supervision system is to properly display the data collected, which can be achieved in variable ways including text, tables, graphs, images, voice and videos, with different functions respectively.

To satisfy different requirements from different clients, the results could be presented in data type, static chart type and dynamic graph type, as are shown in table 1 . The simplest way to describe and display data is text and table while designing graphs is also quite persuasive, especially with regard to time as well as space and some concrete concepts, which makes it irreplaceable by text. Image, voice and video are the objective description of data.

Table 1. Classification of Data Display in Reservoir Resettlement

\begin{tabular}{|c|c|l|}
\hline Classification & \multicolumn{1}{|c|}{ Form } & \multicolumn{1}{c|}{ Data classification } \\
\hline data type & text, table & $\begin{array}{l}\text { data of project planning, owned waters, resettlement area, } \\
\text { administrative area, administrative units }\end{array}$ \\
\hline static chart type & $\begin{array}{l}\text { bar chart, column chart, pie } \\
\text { chart, line chart, area chart }\end{array}$ & $\begin{array}{l}\text { basic economic condition, population distribution, project } \\
\text { funding category }\end{array}$ \\
\hline dynamic graph type & GIS, RS, GPS & $\begin{array}{l}\text { information of reservoir distribution, process of immigration } \\
\text { planning work, data base of immigration village, funding } \\
\text { distribution, etc. }\end{array}$ \\
\hline
\end{tabular}

Situations like demographics and funding arrangement can be easily inquired through this method, which is quite beneficial to the management workers. Delicacy Management (DM) will also be achieved. What is more, such system can establish a synchronization mechanism between system function interface and data, promote the integration and construction of the national immigrant management of information resources and improve the efficiency of management work. In the meantime, supervision effectiveness can be highly optimized by providing immigrants channels to know complete information about the process.

\subsection{Historical Data Management}

In order to make clear the essence of fast changing objective things, it is necessary to link and compare the different stages of the development itself. Through analyzing historical data and revealing its internal contradictions and contact, the nature and laws of reservoir resettlement management can only be grasped [5].

The work of reservoir immigrants have distinct characteristics which is neither formed overnight nor baseless created but the results of exploration and the development of fifty-year experience in resettlement project. The immigrants policies have formed a comparatively perfect policy system after fifty-year development, as is shown in Fig. 1. In order to give a deeper insight of immigrant policies as well as its characteristics and completely understand them, it is necessary to know more about the development of such policies and look into the historical reasons behind the changes, only in this way, problems existed inside can be found out and then give references for future development in immigrant policies.

The development mode was decided by policies that were regulated by executive orders from 
government in Planned Economy during the early days after the founding of the republic. A series of policies were made to jump off this mode, till nowadays, where immigrant policies were constantly adjusted to improve compensation standard as well as safeguards. National investors and enterprises invested a lot of money, resources and continued to strengthen policy adjustment, turning the reservoir immigrants from victims into beneficiaries.

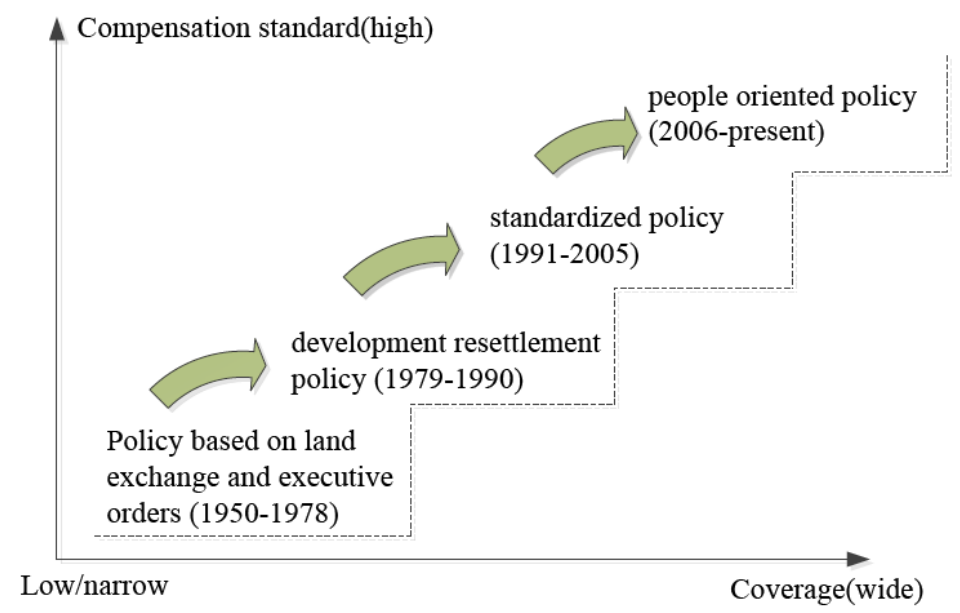

Fig. 1. Historical reservoir resettlement graph.

\subsection{Use of Funding Management}

Use and management of reservoir resettlement project funds is a key component of the entire resettlement project management. With the improvement of immigrant income levels as well as government's support latter, the sources of funding and the number as well as the categories of immigrant projects are greatly increased, therefore it needs to supervise and manage the use of funds. By data analysis from terminal supervision system, a clear record of the situation of resettlement planning and actual investment of funds in the specific cases is presented to help people including immigrant management departments and people who work for them as well as immigrants follow the progress of the project.

The use of reservoir resettlement project funding can be classificated into funding classification, project classification and annual classification, which can both systematically and clearly count and display the distribution and usage of the funds in each level of administrative unit. Resettlement funds can be divided into surplus funds, cash in hand, emergency funds, funds support from each level, self-raised funds, etc. Project classification includes irrigation, infrastructure, production and development, ecology and environment, skills training and vocational education, and other expenses. Funding decentralization and distribution of each reservoir area are counted and analyzed by year in annual classification.

The grasp of management and use in the process of the project is the key element to the success of the whole project. Using terminal supervision system and count project funds by three classifications including funding classification, project classification and annual classification provide users more ways to know about the distribution of funds. In the meantime, problems existing in distribution and use can be timely found by reservoir resettlement stakeholders with the help of such way of classification. Local immigrants will have access to standardized supervision on the use of funds and it can benefit the management department in the next stage of work.

\section{Guangdong Reservoir Resettlement Data Management System}

\subsection{Basic Data Display for Reservoir Resettlement}

Besides excel, bar chart and pie chart for collecting and analyzing information including administrative 
information, basic economic situation and population distribution as well as funding projects distribution, modern technology like GIS is mainly utilized for real-times, continuous and dynamic record of situation of reservoir and resettlement district.

Dynamic Graphics Based Data Management (DGBDM) is to use geographic information systems (GIS), remote sensing (RS), Global Positioning System (GPS) technology for reservoir resettlement work-related data for dynamic presentation, which means it can achieve more effective integration of advanced technology and professional applications in reservoir resettlement by building a reservoir resettlement system. So you can take advantage of $3 \mathrm{~S}$ technology for dynamic display of regional reservoir distribution information, regional planning and progress of reservoir resettlement, immigration to the underlying data, the availability of funds, etc.(as is shown in Fig. 2, Fig. 3).

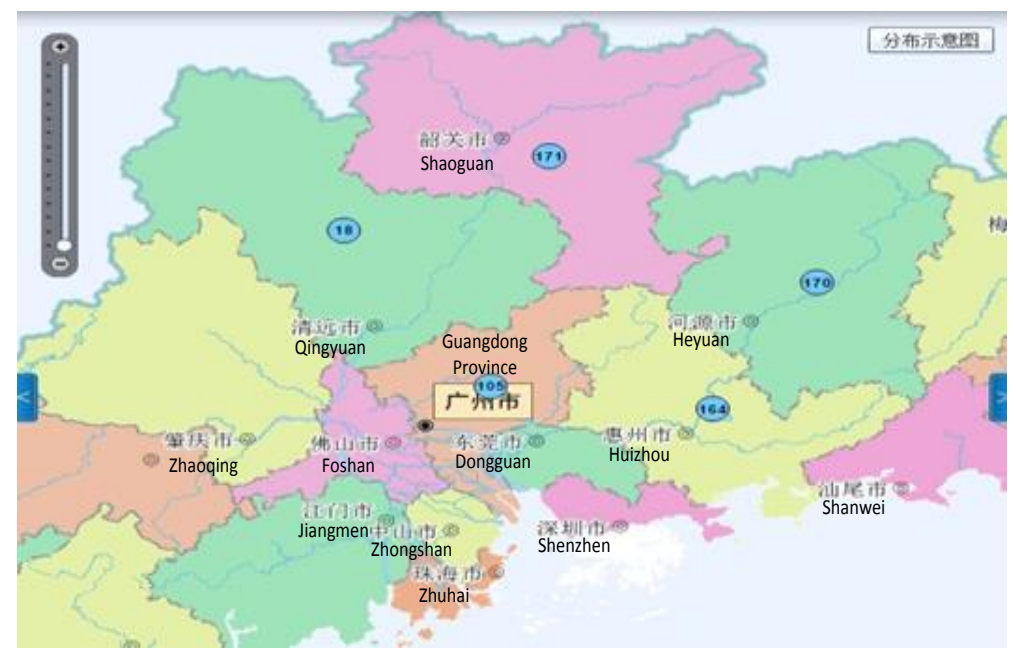

Fig. 2. Guangdong reservoir distribution map.

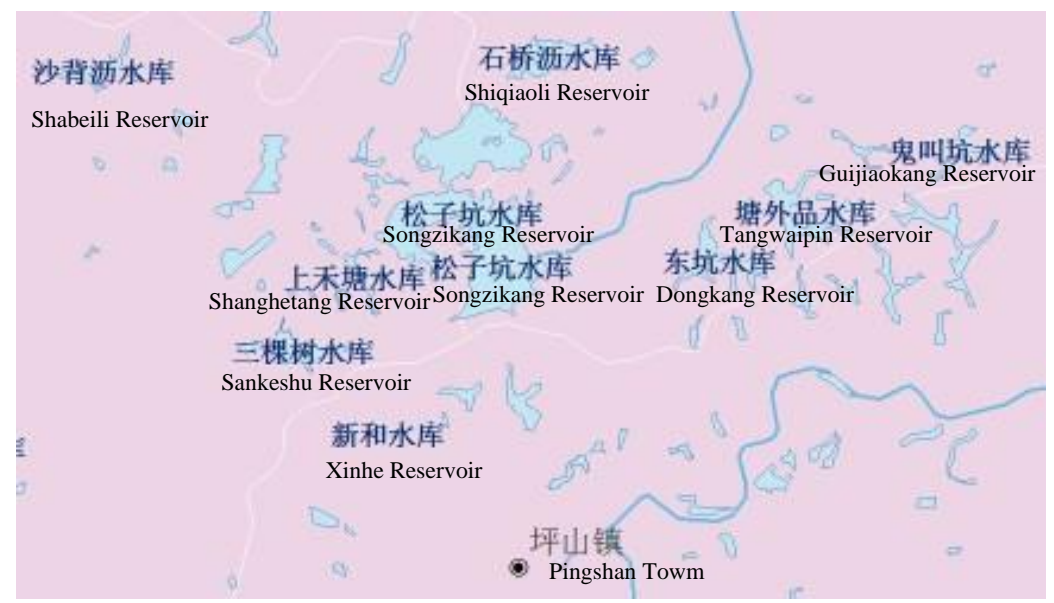

Fig. 3. Detailed reservoir distribution map of Shenzhen, Guangdong Province.

The dynamic charts show the number of reservoir construction and distribution of the reservoirs in Guangdong resettlement project, it also reflects situation of reservoir construction planning and completion, reservoir resettlement and infrastructure and so on from provinces, municipalities and village levels by relevant techniques, which provide comprehensive, dynamic and timely support for the progress of administrators. To start with the existing framework of the organization, interconnections and information sharing mechanism shall be established between resettlement management departments from five levels including province, city, county, town and village, followed by the establishment of system function interface and data synchronization mechanism between departments of different levels. Then it shall facilitate the 
process of information integration and unified construction nation widely.

The reservoir resettlement management information system based on GIS is objective, dynamic, fast, accurate control of macroeconomic indicators and facilitates the implementation of monitoring and management. The establishment of the system will help the immigration investigation, the resettlement plan to implement various stages of the resettlement procedural and standardized, and comprehensively improve the quality and management of the resettlement plan outcomes [6]. With the process of the application, future work mainly focus on further improving function of the system in resettlement management as well as decision support and broadening the application into the decision management during project implementation phase and deepen the application after perfecting all the functions of management and decision support. A common platform for reservoir resettlement is expected to achieved in the future.

\subsection{Historical Allocation of Funds}

The key element to the success of immigrant resettlement is to safely as well as effectively use resettlement funds. As to the resettlement funds is the event funds of national support for immigrants, its use must be earmarking. Through the analysis of use of resettlement funds in each region every year, the law of funds appropriation could be found and grasped, which, on the one hand, can guarantee the specificity of funds, on the other hand, could improve the management of funds and enhance the speed when money is in place as well as reduce the rate of financial credit. This is of great significance to the improvement of management of reservoir resettlement [7]. Bar graphs in Fig. 6 reflect the use of resettlement funds in different aspects each year.

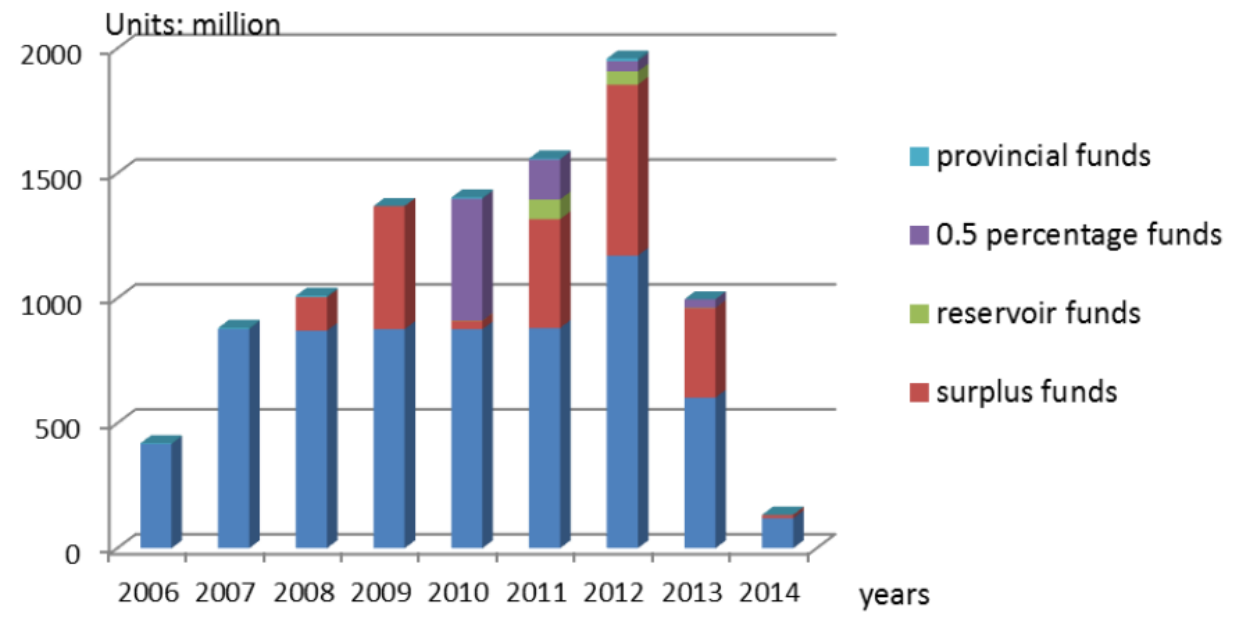

Fig. 4. Funds distribution ratio bar graph.

From the bar graphs above, we can firstly understand the category of resettlement funds project, followed by the situation and the law of the use of funds. For example, project '600 RMB Late Support' occupies a large proportion in the use of funds; Reservoir resettlement funds appropriation in 2012 is the largest among the 9 years. After understanding the economic and social situation and finding the reasons behind the huge differences of different years, references could be provided for the future resettlement work.

Through real-time collection of data by GIS in resettlement district, coupled with its analysis, the benefits are easily achieved includes summarization of policy trends of resettlement work, overall grasp of economic situation of each village, understanding the relationship between various administrative units and different departments in resettlement work, total grasp of information including funds appropriation and distribution, which is of great importance as well as good reference to the management work in reservoir 
resettlement work.

\subsection{Management of Reservoir Resettlement Funds Usage in Guangdong Province}

Through Excel and graphs, users can clearly and directly get access to the funds distribution and usage situation in each city, county, town and village in Guangdong Province. Classified by three aspects including funding classification, project classification and annual classification, information collected can systematically show the distribution and use of resettlement funds in the administrative unit of each level in Guangdong. Each classification is dealt with through refining classifications where funds distribution could be counted by data type.

Take project classification for example, nowadays funds project classification includes individual subsidy, basic household plot and irrigation and water conservancy, infrastructure, social infrastructure, production and development, ecology and environment, skills training and vocational education and other fee. According to administrative division, source of funds and year, the system can clearly display the distribution of the funds in different areas with regard to different years and the source of funds (as is shown in Fig. 5).

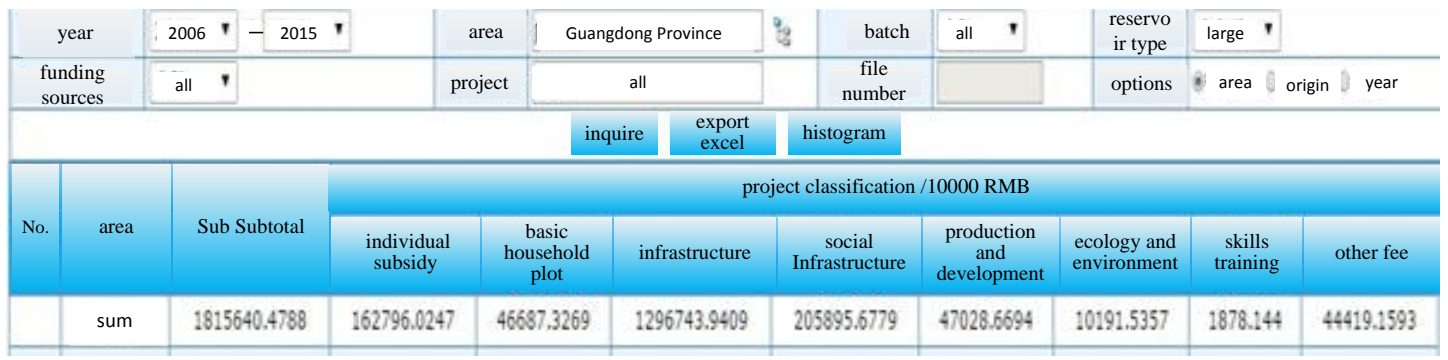

Fig. 5. Guangdong large-sized projects classification.

Through project classification, system users can directly get access to the situation of funding distribution as well as emphasizing major projects, according to which, the differences between mayor projects of each districts are classified in order to provide a guideline for resettlement work accordingly.

At the meantime, taking the requirements of users into consideration, options are designed like reservoir type and planning year and so on, which is quite convenient for users to search for certain distribution of resettlement projects.

\section{Finding}

In Fig. 6 three aspects are displayed including basic data management, historical data management and funds utilization management (merits in practical application), which are the main information in describing a reservoir resettlement management system. Among the three aspects, basic data management is to directly collect and manage engineering information through various ways; historical data management is to use several analyzing methods for digging potential information; funds utilization management is to take better advantage of core resources of the projects and for the sake of anti-corruption after which funds is truly used for solving problems of resettlement immigrants (as is shown in Fig. 6).

Classifications above are implemented in Guangdong reservoir resettlement management project, which covers aspects including basic information, the application, approval, implementation and acceptance of funds projects. It is proved to be quite sufficient in improving management work of resettlement departments and improve the efficiency of funds. It can be seen in the near future that a more effective, systematic and comprehensive resettlement data management system could be applicable in a wider range of situation. 


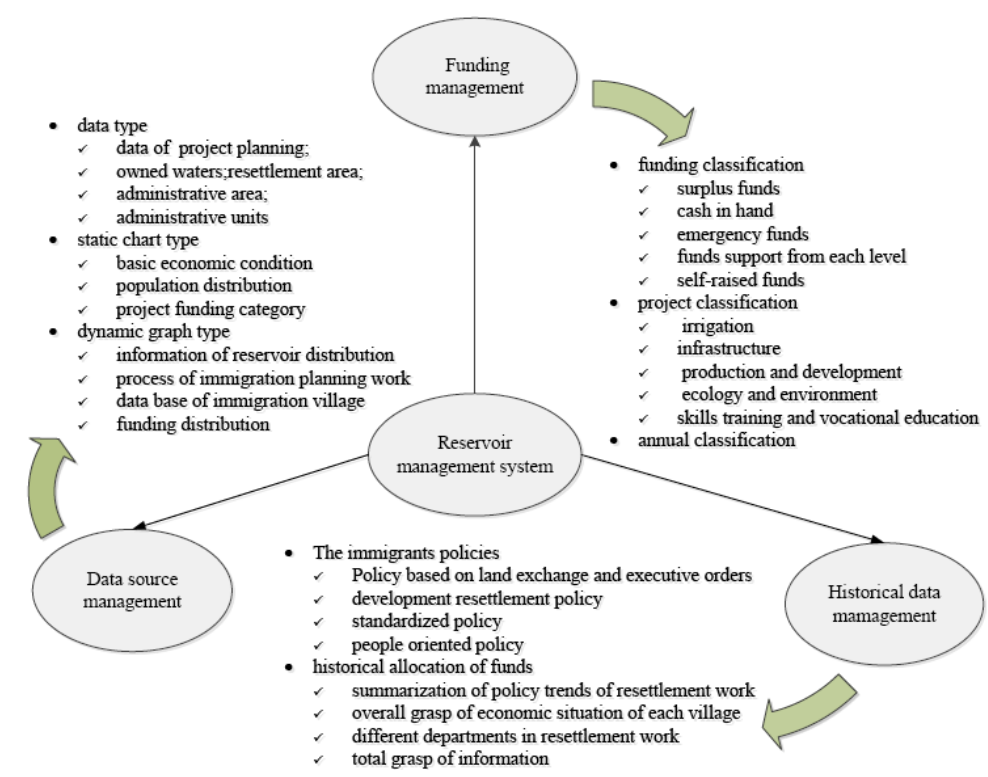

Fig. 6. Structure diagram of reservoir resettlement data management system application.

\section{Conclusion}

Reservoir resettlement data management system displays the situation of various aspects including funds usage, population distribution and project process, with approaches of static and dynamic display as well as funding classification, project classification and annual classification, which make it easier for resettlement government management department and immigrants to get direct access to the basic information and process of the project, whereas it also calls for higher requirements for accuracy and real-time feedback.

Nowadays in China, modern technologies like GIS are widely applied in aspects including resource investigation, disaster prediction, communication, transportation and so on. To be more specific, a highly effective, systematic and convenient management system using modern technologies is the overwhelming trend in resettlement project management, which necessitates research on reservoir resettlement projects and provides a reference and guideline for resettlement information management in more districts.

\section{Acknowledgement}

This paper was supported by "Research on key technology of terminal supervision system in Guangdong reservoir resettlement project" originated from hydro-engineering innovation project in Guangdong province (No. 2012- - 12) and "Terminal Supervision Theory and Practice on Reservoir Resettlement Late Support in Gaungdong' Science and Technology Project of Guangdong Province (No. 2013B070206037)”.

\section{References}

[1] Wei, J. S. (2011). Research on migration theory and reservoir immigration. China Water Resources, 2, 7-10.

[2] Nathalie, S., Clementine, B., \& Daniele, E. (2009). Analyzing spatial drivers in quantitative conflict studies: The potential and challenges of geographic information systems. International Studies Review, 11, 502-522.

[3] Rekha, V. B., Thomas, A. P., Suma, M., \& Vijith, H. (2011). An integration of spatial information technology for groundwater potential and quality investigations in Koduvan Ár Sub-Watershed of Meenachil River Basin, Kerala, India. J Indian Soc Remote, 39, 63-71.

[4] Jorge, V., \& Sergio, T. A.-C. (2014). Influence of kangaroo rat burrows in the spatial organization of the 
San Jose Island rodent community. Journal of Arid Environments, 111, 84-90.

[5] Zhang, X. L. (2014). Research of reservoir resettlement policy of Historical Evolution. Beijing: China University of Geosciences.

[6] Tan, M., Xia, R., \& Zhang, W. (2008). Study of reservoir resettlement management information system based on GIS. Express Water Resources and Hydropower Information, 12, 37-40.

[7] Wang, Y. Z., Li, Z. H., \& Chen, L. (2011). Investigation on the management of support fund in medium-sized reservoir resettlement. Finance and Accounting Monthly, 11, 18-20.

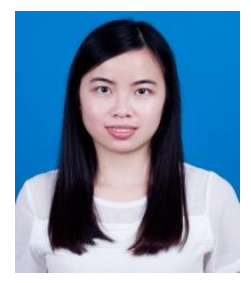

Jiexi Shen was born in Jiangsu Province, China in 1992. She received a B.S. degree of accounting at Jinling Institute of Technology in 2014. She started her research on strategic management at School of Business, Hohai University in Nanjing, China in 2014. Now her research area is mainly focused on water management cooperation.

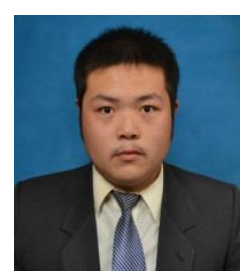

Bailing Zhou was born in Jiangsu Province, China in 1992. He received a B.S degree of electrical engineering and automation in China University of Mining and Technology in 2014. He is now a postgraduate student in State Grid Electric Power Research Institute in Nanjing, China. His current research area is mainly focus on digital space modeling, mathematic modeling. 